\title{
Use of Drugs Subject to Controlled Prescriptions: a Retrospective Analysis
}

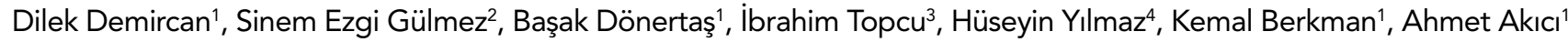 \\ ${ }^{1}$ Department of Pharmacology, Faculty of Medicine, Marmara University, Istanbul, Turkey \\ 2INSERM CIC-P 0005 Pharmacoépidémiologie, Service de Pharmacologie, Université Bordeaux Segalen, Bordeaux, France \\ ${ }^{3}$ Public Health Directorate of istanbul, Istanbul, Turkey \\ ${ }^{4}$ Provincial Health Directorate of istanbul, Istanbul, Turkey
}

\section{ABSTRACT}

Objective: Use of drugs that may lead to abuse or dependence are subject to controlled prescriptions (CPs) in many countries, and these are closely monitored by health authorities. According to national regulations in Turkey, CPs may be red coloured (RCPs) or green coloured (GCPs). The aim of this study was to evaluate the use of such drugs in Istanbul.

Study Design: Retrospective case-control study.

Material and Methods: During the study period (01/01-31/12 2009), 502874 CPs were reported. Among these, 4000 CPs each month were randomly selected and evaluated.

Results: The majority of GCPs were issued to women (55.6\%), while the majority of RCPs were issued to men (68.4\%). GCPs were most frequently prescribed by physicians working in private hospitals (33.6\%) while RCPs by physicians working in university hospitals (39.7\%). GCPs were mostly prescribed by psychiatrists (37.6\%) while for RCPs were child and adolescent psychiatrists (35.9\%). Psycholeptics (ATC code N05) were the most prescribed controlled drugs (CDs) (43.8\%). Methylphenidate (53.9\%) was the mostly prescribed on RCPs and alprazolam (39.6\%) was on GCPs.

Conclusion: We demonstrate that utilization of CDs shows demographical and institutional differences. These data could be of help to improve surveillance of $C D$ s as well as to train prescribers and patients.

Key Words: Controlled prescriptions, controlled medicines, narcotics, psychotropic medications, green and red coloured scripts

\section{Introduction}

The use of drugs that may lead to abuse or dependence are limited by national and international regulations, and are subject to controlled prescriptions (CPs) in many countries that are closely monitored by health authorities (1-6). According to national regulations in Turkey, CPs may be red coloured (RCPs) or green coloured (GCPs). Narcotic analgesics and methylphenidate drugs that are controlled according to Single Convention on Narcotic Drugs, should be issued on RCPs maximum for 10 days use (1). Drugs with abuse or dependence potential; psychotropic medications such as barbiturates and benzodiazepines that are controlled according to the Convention on Psychotropic Substances are issued on GCPs. Such CPs should contain three sheets; one original and two copies, one of which has to be sent monthly to the local health authorities $(2,5,6)$.

Although controlled drugs (CDs) have the risk of abuse, their medical use has vital importance in the treatment of important health problems $(7,8)$. The monitoring of CPs and rational use of drugs concerned by these need detailed pharmacoepidemiological studies. In the literature, studies that have investigated use of CDs have mainly focusing on specific diagnoses or specific patient populations (9-16). The aim of this study was to evaluate the use of such drugs in Istanbul, Turkey's biggest metropolis.

\section{Material and Methods}

\section{Data collection}

All CPs (RCPs and GCPs) from all districts of Istanbul are transmitted to Provincial Directorate of Health in Istanbul on a monthly basis $(5,6)$. All CPs are handwritten and archived as original hard copies. Among the CPs (RCPs and GCPs) issued between the $1^{\text {st }}$ of January 2009 and the $31^{\text {st }}$ of December 2009 (study period) archived by the Provincial Health Directorate of istanbul, a sample of 4000 for each month were randomly selected and retrospectively evaluated. CPs were anonymously coded to avoid patient identification, and then data was extracted and entered into the study database in a standardized manner (using ATC [Anatomical Therapeutic Chemical] classification for drugs, and ICD-10 codes [International Statistical Classification of Diseases and Related Health Problems] for diagnoses). 


\section{Statistical Analysis}

Statistical analyses were carried out by Microsoft Excel and SPSS v.11.0 programs. Statistical comparisons were based on Chi-square test at a $p<0.05$ level of significance.

\section{Results}

During the study period, 463811 CPs were issued (88094 RCPs, and 375717 GCPs), and $10.3 \%$ of these $(n=48000)$ were evaluated here. Among these CPs, 78.9\% $(n=37868)$ were GCPs, and 21.1\% ( $n=10132)$ were RCPs. A total of 50792 drugs were prescribed on CPs and $78.1 \%$ of them were on GCPs and $21.9 \%$ of them were on RCPs.

Almost one third of all CPs (31.9\%) did not specify the prescribed dose. A minority (5.8\%) did not contain information on pharmaceutical form, and among those that did $(n=47860)$, $78.3 \%$ were tablets. Over two-thirds of CPs (69.0\%) did not indicate patient age, and $2.2 \%$ omitted gender. When gender was noted, $50.6 \%$ were women. GCPs were issued more frequently to women $(55.6 \%)$, while RCPs were more frequently issued to men $(68.4 \%),(p<0.05)$.

Mean (SD) age, when noted ( $n=14856,31.0 \%)$, was 45.9 years (20.5). CPs were mostly issued to patients aged between $45-64$ years (38.0\%). When GCPs and RCPs were compared by age groups, except for 18-44 age group, RCPs were mostly prescribed in all other age groups and this difference was statistically significant $(p<0.05)$, (Table 1$)$.

Controlled prescriptions were most frequently issued by physicians working in private hospitals (30.3\%) followed by those who worked in state hospitals (27.7\%), primary healthcare centers (18.7\%), and university hospitals (15.3\%). GCPs were most frequently issued by physicians working in private hospitals (33.6\%), while RCPs were more frequently issued by physicians working in university hospitals $(39.7 \%),(p<0.05)$ (Table 2).

Among $\mathrm{CPs}$ indicating physician specialty, the most frequent prescribers were psychiatrists (33.3\%), internists (13.1\%), and neurologists (12.0\%). GCPs were mostly issued by psychiatrists (37.6\%), neurologists (15.6\%), and internists $(15.5 \%)$, while for RCPs were mostly issued by child and adolescent psychiatrists (35.9\%), psychiatrists (21.2\%), and anaesthesiologists (14.0\%) (Table 3). The majority of CPs $(86.0 \%)$ were prescribed by internal medicine specialists $(87.1 \%$ in GCPs and $82.8 \%$ in RCPs). Fourteen per cent of the CPs were prescribed by physicians from surgical specialties $(12.9 \%$ in GCPs and $17.2 \%$ in RCPs).

Distribution of the first three prescribed drugs according to physicians' specialty were evaluated. Alprazolam was most frequently issued drug by internists (46.1\%), neurologists $(46.1 \%)$, general practitioners (43.7\%), family practitioners (41.0\%), psychiatrists (37.7\%), and general surgeons (31.0\%). Tramadol was most frequently issued by physical therapy and rehabilitation specialists $(85.1 \%)$, orthopaedists $(66.1 \%)$, neurosurgeons $(52.4 \%)$, and anaesthetists (37.9\%). Fentanyl was most frequently issued by radiation oncologists (57.4\%), and medical

Table 1. Distribution of controlled prescriptions by age groups

\begin{tabular}{|c|c|c|c|c|}
\hline Age (years) & $\begin{array}{l}\text { GCPs, } \\
\text { n (\%) }\end{array}$ & $\begin{array}{c}\text { RCPs, } \\
\text { n (\%) }\end{array}$ & $\begin{array}{c}\text { Total CPs, } \\
\text { n (\%) }\end{array}$ & $\begin{array}{c}\text { Statistic } \\
\text { (Chi-square) }\end{array}$ \\
\hline$<18$ & $\begin{array}{l}1116 \\
(9.5)\end{array}$ & $\begin{array}{c}621 \\
(20.0)\end{array}$ & $\begin{array}{l}1737 \\
(11.7)\end{array}$ & \\
\hline $18-44$ & $\begin{array}{l}4225 \\
(36.0)\end{array}$ & $\begin{array}{l}510 \\
(16.4)\end{array}$ & $\begin{array}{l}4735 \\
(31.9)\end{array}$ & \\
\hline $45-64$ & $\begin{array}{l}4438 \\
(37.8)\end{array}$ & $\begin{array}{c}1214 \\
(39.1)\end{array}$ & $\begin{array}{l}5652 \\
(38.0)\end{array}$ & $p<0.05$ \\
\hline$\geq 65$ & $\begin{array}{l}1969 \\
(16.8)\end{array}$ & $\begin{array}{c}763 \\
(24.5)\end{array}$ & $\begin{array}{l}2732 \\
(18.4)\end{array}$ & \\
\hline Total* & $\begin{array}{l}11748 \\
(100.0)\end{array}$ & $\begin{array}{c}3108 \\
(100.0)\end{array}$ & $\begin{array}{l}14856 \\
(100.0)\end{array}$ & \\
\hline $\begin{array}{l}\text { *Only the presc } \\
\text { GCPs: Green co } \\
\text { CPs: Controlled }\end{array}$ & $\begin{array}{l}\text { Is with da } \\
\text { d prescrip } \\
\text { riptions }\end{array}$ & on patie & $\begin{array}{l}i^{\prime} \text { age wer } \\
\text { Red colour }\end{array}$ & $\begin{array}{l}\text { nalyzed } \\
\text { prescriptions, }\end{array}$ \\
\hline
\end{tabular}

Table 2. Distribution of controlled prescriptions by healthcare centers

\begin{tabular}{|c|c|c|c|c|}
\hline & GCPs, n (\%) & RCPs, n (\%) & Total CPs, n (\%) & $\begin{array}{c}\text { Statistic } \\
\text { (Chi-square) }\end{array}$ \\
\hline \multicolumn{5}{|l|}{ Healthcare Centers } \\
\hline Private hospitals & $12734(33.6)$ & $1825(18.0)$ & $14559(30.3)$ & \\
\hline \multicolumn{5}{|l|}{ State hospitals } \\
\hline Training & $5052(13.3)$ & $2181(21.5)$ & $7233(15.1)$ & \\
\hline Other state & $4861(12.8)$ & $815(8.0)$ & $5676(11.8)$ & \\
\hline Military & $284(0.8)$ & $89(0.9)$ & $373(0.8)$ & $p<0.05$ \\
\hline Primary healthcare centers & $8871(23.4)$ & $88(0.9)$ & 8959 (18.7) & \\
\hline University hospitals & $3307(8.7)$ & $4020(39.7)$ & $7327(15.3)$ & \\
\hline Consulting rooms & $2320(6.1)$ & $1094(10.8)$ & $3414(7.1)$ & \\
\hline Workplace physicians & $355(0.9)$ & $2(0.0001)$ & $357(0.7)$ & \\
\hline Others & $76(0.2)$ & $18(0.2)$ & $94(0.2)$ & \\
\hline Total & $37860(100.0)$ & $10132(100.0)$ & $47992(100.0)$ & \\
\hline
\end{tabular}


Table 3. Distribution of controlled prescriptions by physicians' specialty

\begin{tabular}{|lccc|}
\hline & \multicolumn{3}{c}{ Controlled prescription } \\
& GCPs, n (\%) & RCPs, n (\%) & Total, n (\%) \\
\hline Psychiatry & $10442(37.6)$ & $2088(21.2)$ & $12530(33.3)$ \\
Internal medicine & $4303(15.5)$ & $619(6.3)$ & $4922(13.1)$ \\
Neurology & $4343(15.6)$ & $154(1.6)$ & $4497(12.0)$ \\
Child and adolescent & $209(0.8)$ & $3535(35.9)$ & $3744(10.0)$ \\
psychiatry & & & \\
Anaesthesia & $1349(4.9)$ & $1378(14.0)$ & $2727(7.2)$ \\
Paediatrics & $1601(5.8)$ & $87(0.9)$ & $1688(4.5)$ \\
Radiation oncology & $474(1.7)$ & $978(9.9)$ & $1452(3.9)$ \\
General surgery & $582(2.1)$ & $175(1.8)$ & $757(2.0)$ \\
Physical therapy and & $734(2.6)$ & $14(0.1)$ & $748(2.0)$ \\
rehabilitation & & & \\
Neurosurgery & $624(2.2)$ & $43(0.4)$ & $667(1.8)$ \\
Medical oncology & $225(0.8)$ & $361(3.7)$ & $586(1.6)$ \\
Family medicine & $539(1.9)$ & $30(0.3)$ & $569(1.5)$ \\
Chest diseases & $286(1.0)$ & $271(2.7)$ & $557(1.5)$ \\
General practitioner & $280(1.0)$ & $8(0.1)$ & $288(0.8)$ \\
Orthopaedics & $365(1.3)$ & $8(0.1)$ & $373(1.0)$ \\
Others & $1409(5.1)$ & $111(1.1)$ & $1520(4.0)$ \\
Total* & $27765(100.0)$ & $9860(100.0)$ & $37625(100.0)$ \\
\hline *Only the prescriptions issued with physicians' specialty were analyzed \\
GCPs: Green coloured prescriptions, RCPs: Red coloured prescriptions, \\
CPs: Controlled prescriptions & & & \\
\hline & & & \\
\hline
\end{tabular}

oncologists (46.4\%). Child and adolescent psychiatrists most frequently issued methylphenidate (93.9\%), and chest physicians most frequently issued codeine (24.3\%) (Table 4).

Among the 50792 prescribed drugs, psycholeptics (43.8\%) were most frequently issued therapeutic class, followed by analgesics (19.1\%), antiepileptics (13.2\%), psychoanaleptics (11.9\%), antiparkinson drugs $(9.6 \%)$, codeine $(2.2 \%)$ and anesthetics (0.2\%). GCPs were mostly for psycholeptics (56.1\%), followed by antiepileptics (16.9\%), analgesics (14.4\%), antiparkinson drugs $(12.3 \%)$ and codeine $(0.1 \%)$ while RCPs were mostly for psychoanaleptics (53.9\%), followed by analgesics $(35.6 \%)$, codeine $(9.7 \%)$, anesthetics $(0.6 \%)$ and psycholeptics (0.1\%) (Figure 1). With regards to individual drugs, alprazolam (31.0\%) was mostly issued on CPs followed by methylphenidate $(11.8 \%)$, tramadol $(11.2 \%)$, biperiden (9.6\%), clonazepam (8.0\%), diazepam (7.2\%), fentanyl (6.0\%), phenobarbital (5.2\%), lorazepam (2.3\%) and codeine (2.2\%). With regards to CPs type, alprazolam (39.6\%) was mostly issued on GCPs followed by tramadol (14.4\%), biperiden (12.3\%), clonazepam (10.2\%), diazepam (9.3\%), phenobarbital (6.6\%), lorazepam (2.9\%), chlordiazepoxide (1.8\%), zopiclone (1.2\%) and clorazepate $(0.7 \%)$. Methylphenidate $(53.9 \%)$ was most frequently issued drug on RCPs, followed by fentanyl (27.5\%), codeine $(9.7 \%)$, morphine $(5.1 \%)$, pethidine $(3.0 \%)$, remifentanyl $(0.6 \%)$, and alfentanyl (0.04\%) (Figure 2).
Table 4. Distribution of the first three prescribed drugs according to physicians' specialty

\begin{tabular}{|c|c|c|c|}
\hline & & ntrolled prescripti & ion \\
\hline & Type & Drug prescribed & n (\%*) \\
\hline Psychiatry $(n=13073)$ & GCP & Alprazolam & $4930(37.7)$ \\
\hline & GCP & Biperiden & $2592(19.8)$ \\
\hline & $\mathrm{RCP}$ & Methylphenidate & $2125(16.3)$ \\
\hline Internal medicine & GCP & Alprazolam & $2397(46.1)$ \\
\hline$(n=5198)$ & GCP & Tramadol & $890(17.1)$ \\
\hline & $\mathrm{RCP}$ & Fentanyl & $473(9.1)$ \\
\hline Neurology $(n=4673)$ & GCP & Alprazolam & $2154(46.1)$ \\
\hline & GCP & Clonazepam & $631(13.5)$ \\
\hline & GCP & Diazepam & $553(11.8)$ \\
\hline Child and adolescent & $\mathrm{RCP}$ & Methylphenidate & 3633 (93.9) \\
\hline psychiatry $(n=3869)$ & GCP & Phenobarbital & $76(2.0)$ \\
\hline & GCP & Clonazepam & $40(1.0)$ \\
\hline Anaesthesia $(n=3132)$ & $\mathrm{GCP}$ & Tramadol & 11087 (37.9) \\
\hline & $\mathrm{RCP}$ & Fentanyl & 873 (27.9) \\
\hline & $\mathrm{RCP}$ & Codeine & $526(16.8)$ \\
\hline Paediatrics $(n=1748)$ & GCP & Phenobarbital & $1060(60.6)$ \\
\hline & GCP & Clonazepam & $282(16.1)$ \\
\hline & GCP & Diazepam & $176(10.1)$ \\
\hline Radiation oncology & $\mathrm{RCP}$ & Fentanyl & $969(57.4)$ \\
\hline$(n=1688)$ & GCP & Tramadol & $408(24.2)$ \\
\hline & GCP & Alprazolam & $102(6.0)$ \\
\hline General surgery & GCP & Alprazolam & $253(31.0)$ \\
\hline$(n=816)$ & GCP & Tramadol & $153(18.8)$ \\
\hline & $\mathrm{RCP}$ & Pethidine & $94(11.5)$ \\
\hline Physical therapy and & GCP & Tramadol & $661(85.1)$ \\
\hline rehabilitation $(n=777)$ & GCP & Alprazolam & $58(7.5)$ \\
\hline & GCP & Diazepam & $28(3.6)$ \\
\hline Neurosurgery $(n=727)$ & GCP & Tramadol & $381(52.4)$ \\
\hline & GCP & Alprazolam & $161(22.1)$ \\
\hline & GCP & Phenobarbital & $59(8.1)$ \\
\hline Medical oncology & $\mathrm{RCP}$ & Fentanyl & $311(46.4)$ \\
\hline$(n=670)$ & GCP & Tramadol & $164(24.5)$ \\
\hline & $\mathrm{RCP}$ & Codeine & $81(12.1)$ \\
\hline Family medicine & $\mathrm{GCP}$ & Alprazolam & $238(41.0)$ \\
\hline$(n=580)$ & GCP & Clonazepam & $63(10.9)$ \\
\hline & GCP & Tramadol & $62(10.7)$ \\
\hline Chest diseases $(n=617)$ & $\mathrm{RCP}$ & Codeine & $150(24.3)$ \\
\hline & $\mathrm{RCP}$ & Fentanyl & $149(24.1)$ \\
\hline & GCP & Tramadol & $130(21.1)$ \\
\hline General practitioner & GCP & Alprazolam & $138(43.7)$ \\
\hline$(n=316)$ & GCP & Diazepam & 45 (14.2) \\
\hline & GCP & Tramadol & $34(10.8)$ \\
\hline Orthopaedics $(n=407)$ & GCP & Tramadol & $269(66.1)$ \\
\hline & GCP & Alprazolam & $102(25.1)$ \\
\hline & GCP & Diazepam & $4(1.0)$ \\
\hline $\begin{array}{l}\text { *By the total number of medic } \\
\text { GCPs: Green coloured prescri } \\
\text { Controlled prescriptions }\end{array}$ & cines pre & bed in related spec & $\begin{array}{l}\text { ies } \\
\text { iptions, CPs: }\end{array}$ \\
\hline
\end{tabular}




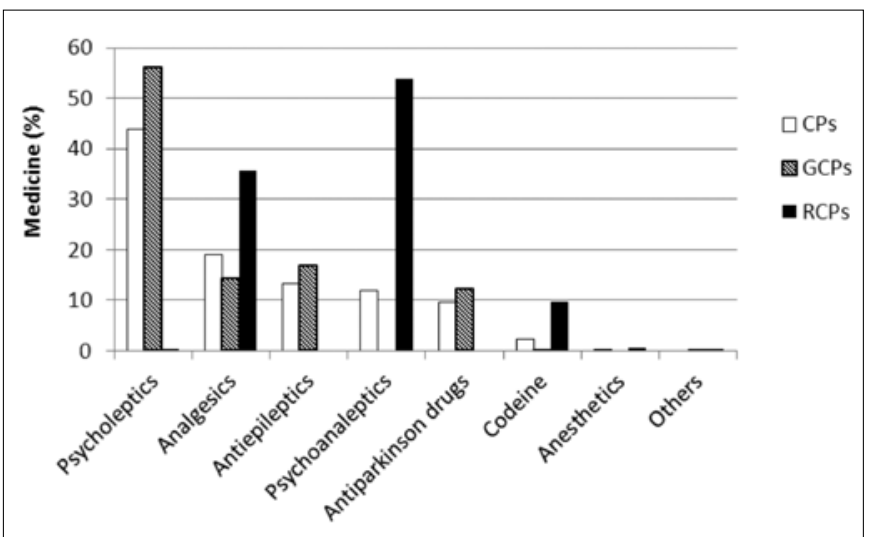

Figure 1. Distribution of the drugs subject to control by main therapeutic classes

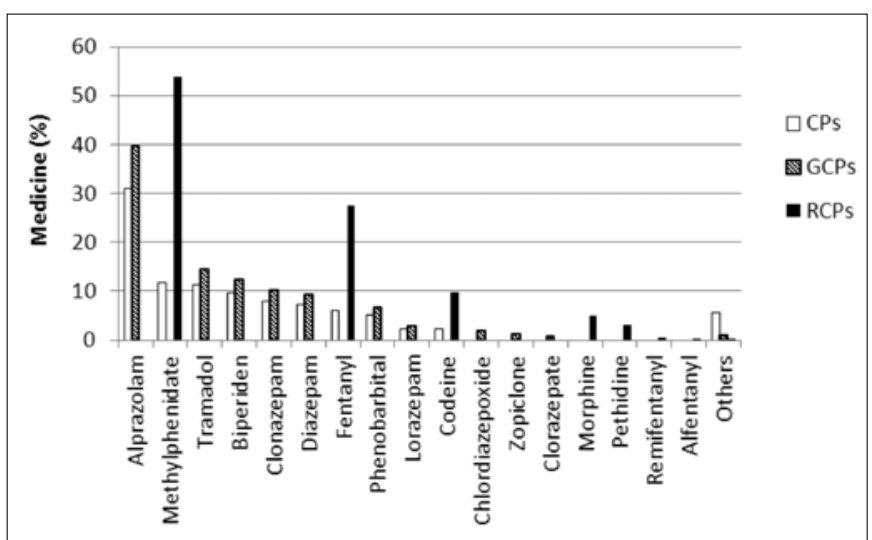

Figure 2. Distribution of drugs subject to control by ATC-5 classification

Table 5. Distribution of the diagnoses written out on controlled prescriptions

\begin{tabular}{|c|c|c|c|}
\hline & GCPs, n (\%) & RCPs, n (\%) & Total CPs, n (\%) \\
\hline \multicolumn{4}{|l|}{ Diagnose (ICD-10 Code) } \\
\hline Other anxiety disorders (F41) & $11893(32.9)$ & $36(0.4)$ & $11929(26.0)$ \\
\hline Depressive episode (F32) & $6721(18.6)$ & $47(0.5)$ & $6768(14.7)$ \\
\hline Neoplasms (C00-D48) & $2255(6.2)$ & $3523(36.1)$ & $5778(12.6)$ \\
\hline Hyperkinetic disorders (F90) & - & $5696(58.3)$ & $5696(12.4)$ \\
\hline Epilepsy (G40) & $4122(11.4)$ & - & $4122(9.0)$ \\
\hline Unspecified non-organic psychosis (F29) & $2176(6.0)$ & - & $2176(4.7)$ \\
\hline Pain, not elsewhere classified (R52) & $1706(4.7)$ & $247(2.5)$ & $1953(4.3)$ \\
\hline Schizophrenia (F20) & $1854(5.1)$ & - & $1854(4.0)$ \\
\hline Bipolar affective disorder (F31) & $1160(3.2)$ & - & $1160(2.5)$ \\
\hline Non-organic sleep disorders (F51) & $744(2.1)$ & - & $744(1.6)$ \\
\hline Dorsalgia (M54) & $511(1.4)$ & $37(0.4)$ & $548(1.2)$ \\
\hline Other spondylopathies (M48) & - & $19(0.2)$ & $19(0.04)$ \\
\hline Other peripheral vascular diseases (173) & - & $19(0.2)$ & $19(0.04)$ \\
\hline Other deforming dorsopathies (M43) & - & $8(0.1)$ & $8(0.02)$ \\
\hline Other soft tissue disorders, not elsewhere classified (M79) & - & $9(0.1)$ & $9(0.02)$ \\
\hline Others & $2981(8.3)$ & $130(1.3)$ & $3111(6.8)$ \\
\hline Total & $36123(100.0)$ & $9771(100.0)$ & $45894(100.0)$ \\
\hline
\end{tabular}

Only 45894 (95.6\%) of all CPs could be stratified by ICD-10 codes as not all handwriting was legible. The most frequent indication was other anxiety disorders $(26.0 \%)$, followed by depressive episode (14.7\%), neoplasms (12.6\%), and hyperkinetic disorders (12.4\%). According to prescription type, among GCPs the most frequent indication was other anxiety disorders (32.9\%), followed by depressive episode (18.6\%), and epilepsy (11.4\%); among RCPs most frequent indication was hyperkinetic disorders (58.3\%), followed by neoplasms (36.1\%) (Table 5).

The most frequent medicines prescribed for the ten most frequent indications were evaluated. For anxiety disorders, depressive episodes, and non-organic sleep disorders alprazolam was the most frequently prescribed medicine $(70.9 \%$,
$68.3 \%$, and $36.0 \%$, respectively). For neoplasms this was fentanyl (42.0\%), for hyperkinetic disorders this was methylphenidate (99.0\%); for epilepsy this was phenobarbital (51.1\%); for unspecified non-organic psychosis, schizophrenia, and bipolar affective disorder this was biperiden $(65.9 \%, 85.0 \%$, and $49.3 \%$, respectively) and for pain not elsewhere classified this was tramadol (79.7\%) (Table 6).

\section{Discussion}

The evaluation of CPs not only provides information on use of these drugs, but also serves as potential data sources for structural regulations. Such field studies could have poten- 
tial importance in countries without electronic prescription databases, such as Turkey. The CPs are in two different types in Turkey, and the proportion of GCPs and RCPs is important to know for regulations and prescription monitoring. We found that the majority of CPs were GCPs (78.9\%). This finding alone points out that drugs prescribed by GCPs and RCPs should be controlled by separate regulations.

Rational prescribing requires the exact amount of active substance to be mentioned, and this has particular importance for CPs $(17,18)$. The Drug Authority of Turkish Ministry of Health has indicated the maximum dose of CDs that should be issued on RCPs (6). We have identified that almost one third of all CPs (31.9\%) did not contain the active substance information, suggesting that physicians did not act rational while prescribing those drugs.

Another important rule for rational prescribing is indicating patient age, particularly for the children. However, in our study, over two-thirds of CPs did not indicate patient age. Physicians are either more careful while prescribing CPs for children $(17,18)$. CPs were more frequently issued to patients aged $45-64$ years (38.0\%). Moreover, there were differences among the age groups for the proportion of GCPs and RCPs. For instance, it was found that for the 18-44 age group, GCPs (36.0\%) were more frequently prescribed than RCPs (16.4\%) while for the patients aged $<18$ years, RCPs (20.0\%) were more prescribed than GCPs (9.5\%) (Table 1). This difference for the patients aged $<18$ years could be related to the CPs for the treatment of hyperkinetic disorders, and the CPs for the treatment of anxiety and depressive disorders in patients aged 18-44 years. Hyperkinetic disorders among child/adolescents and anxiety disorders among adults are more commonly observed (19-24).

Some diseases could be more extensively cured in certain health institutions based on their healthcare service capacity. We found that GCPs were most frequently prescribed at private hospitals (33.6\%), while RCPs at university hospitals (39.7\%) (Table 2). This difference could be due to the predominant distribution of child and adolescent psychiatrists' in university hospitals, in Turkey (25).

When GCPs were analyzed according to diagnosis, more than half of the diagnosis were anxiety and depressive disorders $(51.5 \%)$, and psycholeptics $(56.1 \%)$, mostly benzodiazepines, were mostly prescribed. On the other hand, diagnosis for $58.3 \%$ of RCPs were hyperkinetic disorders, psychoanaleptics $(53.9 \%)$ were the most frequently prescribed. In our study GCPs were mostly prescribed for women and anxiety and depressive disorders while RCPs for mostly men and hyperkinetic disorders correlate well with the fact that in women anxiety disorders and in men hyperkinetic disorders are more common (26-29). In the studies carried out in various countries that investigated the utilization of psychotropic drugs, benzodiazepines were the most frequently prescribed (30-32). Moreover, a study from Bosnia\&Herzegovina noted that among the nervous system drugs, psycholeptics and psychoanaleptics were commonly used drug groups (33).

One of interesting findings was that only $2.3 \%$ of the CPs were prescribed in primary healthcare including family physicians and general practitioners (Table 2). A new health system reform is being implemented in Turkey, and according to this new health system, family practitioners, a new specialization in Turkey, will be constituted. Therefore, the reasons for this low rate should be evaluated in order to prevent patients' unjust treatment (34). According to the IMS Health report on $\mathrm{Na}$ tional Prescription Audit (NPA), in America, the proportion of the prescriptions for psychotropic drugs by primary care physicians increased by $10.6 \%$ from 1996 to 2001 and they were responsible for the $80 \%$ of all anxiolytic and $65 \%$ of antidepressant prescriptions. This increase was correlated with the national legislation about primary care settings (35). Following the integration of the structural regulation process in primary care, in Turkey, proportion of the psychotropic medication prescribing is estimated to increase. Undoubtedly, some of these medications will include CDs. Therefore, it would be better to get prepared for this progress and its consequences.

When the distribution of the first three drugs prescribed for the most frequent 10 diagnoses were evaluated, it was found that alprazolam was preferred for anxiety/depressive episodes; fentanyl and tramadol for cancer; methylphenidate for hyperkinetic disorders; phenobarbital for epilepsy; biperiden for unspecified non-organic psychosis, schizophrenia, and bipolar affective disorder; tramadol for pain (not elsewhere classified); alprazolam and zopiclon for non-organic sleep disorders (Table 6). A study from multiple countries (France, Germany, Italy, UK) and other study from Thailand, lorazepam (31, 32); two studies from Bosnia\&Herzegovina and UK diazepam was the mostly prescribed anxiolytic $(33,36)$. It can be deduced that while benzodiazepines are commonly preferred for anxiety disorders; the first preferred drug can vary by countries. Opioid analgesics are widely used for the treatment of cancer pain. According to the 2010 report of the International Narcotics Control Board, worldwide opioid analgesic consumption for the treatment of pain increased, but it still remains below the expected levels $(37,38)$. In the literature, studies investigated the consumption of opioids revealed different opioid analgesic use. For instance, predominantly used opioid was codeine in Australia and Norway; tramadol was in Bosnia \& Herzegovina $(33,39,40)$. The study from Norway reported that tramadol was among the commonly used opioid for non-cancer pain and fentanyl was for cancer pain and these findings were found correlated with our results (40).

The strengths of our study are, first, through retrieval and ascertainment of a large number of CPs, all of which were reviewed manually by the same person. Second, we had valid prescription data that prescriptions evaluated were archived as original hard copies. Third, this is the first descriptive study on utilization of CPs in Turkey also for structural health regulations.

Our study had some limitations. Due to ethical considerations, patient and physician identifiable data were not collected. Therefore, prescription patterns by individual physician or drug use patterns for individual patient could not be evaluated. Furthermore, additional intervention was not performed for the validation of diagnosis and other information found on the prescriptions. The number of CPs were kept high (4000 CPs/month) to minimize the effect of duplicated data.

In this study, utilization of CDs showed demographical and institutional differences. In general, CDs prescribed on CPs 
Table 6. Distribution of the first three drugs prescribed for the most frequent 10 diagnoses

\begin{tabular}{|c|c|c|c|}
\hline \multirow[b]{2}{*}{ Diagnose (ICD-10 Code) } & \multicolumn{3}{|c|}{ Controlled prescription } \\
\hline & Type & Drugs prescribed & $n(\%)$ \\
\hline \multirow[t]{4}{*}{ Other anxiety disorders (F41) } & GCP & Alprazolam & $8744(70.9)$ \\
\hline & GCP & Diazepam & $1597(13.0)$ \\
\hline & GCP & Clonazepam & $648(5.3)$ \\
\hline & & Others & $1344(11.8)$ \\
\hline \multirow{4}{*}{ Depressive episode (F32) } & GCP & Alprazolam & $4773(68.3)$ \\
\hline & GCP & Diazepam & 739 (10.6) \\
\hline & GCP & Clonazepam & $562(8.1)$ \\
\hline & & Others & $910(13.0)$ \\
\hline \multirow[t]{4}{*}{ Neoplasms (C00-D48) } & $\mathrm{RCP}$ & Fentanyl & $2818(42.0)$ \\
\hline & GCP & Tramadol & $1963(29.3)$ \\
\hline & $\mathrm{RCP}$ & Codeine & $840(12.5)$ \\
\hline & & Others & $1083(16.3)$ \\
\hline \multirow[t]{4}{*}{ Hyperkinetic disorders (F90) } & $\mathrm{RCP}$ & Methylphenidate & $5842(99.0)$ \\
\hline & $\mathrm{RCP}$ & Fentanyl & $18(0.3)$ \\
\hline & GCP & Clonazepam & $9(0.2)$ \\
\hline & & Others & $29(0.5)$ \\
\hline \multirow[t]{4}{*}{ Epilepsy (G40) } & GCP & Phenobarbital & $2189(51.1)$ \\
\hline & GCP & Clonazepam & $1619(37.8)$ \\
\hline & GCP & Diazepam & $278(6.5)$ \\
\hline & & Others & $197(4.6)$ \\
\hline \multirow[t]{4}{*}{ Unspecified non-organic psychosis (F29) } & GCP & Biperiden & $1525(65.9)$ \\
\hline & GCP & Alprazolam & $233(10.1)$ \\
\hline & GCP & Clonazepam & $217(9.4)$ \\
\hline & & Others & $339(14.6)$ \\
\hline \multirow[t]{4}{*}{ Pain, not elsewhere classified (R52) } & GCP & Tramadol & $1600(79.7)$ \\
\hline & $\mathrm{RCP}$ & Codeine & $99(4.9)$ \\
\hline & $\mathrm{RCP}$ & Fentanyl & $82(4.1)$ \\
\hline & & Others & $226(12.3)$ \\
\hline \multirow[t]{4}{*}{ Schizophrenia (F20) } & GCP & Biperiden & $1672(85.0)$ \\
\hline & GCP & Clonazepam & $102(5.2)$ \\
\hline & GCP & Alprazolam & $82(4.2)$ \\
\hline & & Others & $112(5.6)$ \\
\hline \multirow[t]{4}{*}{ Bipolar affective disorder (F31) } & GCP & Biperiden & $605(49.3)$ \\
\hline & GCP & Alprazolam & $234(19.1)$ \\
\hline & $\mathrm{GCP}$ & Clonazepam & $151(12.3)$ \\
\hline & & Others & $237(19.3)$ \\
\hline \multirow[t]{4}{*}{ Non-organic sleep disorders (F51) } & GCP & Alprazolam & $276(36.0)$ \\
\hline & GCP & Zopiclone & $249(32.5)$ \\
\hline & GCP & Clonazepam & $130(16.9)$ \\
\hline & & Others & $112(14.6)$ \\
\hline
\end{tabular}

were compatible with the diagnosis. In contrast to this, missing information on active substance, patient age and gender on the considerable amount of CPs suggested that physicians' performance was not enough with regard to rational prescribing. All these findings should be taken into consideration while developing CPs follow-up systems and building national/international regulations.
Ethics Committee Approval: Ethical approval was received from Istanbul 3 Numbered Clinical Trials Ethics Committee (Ethics approval number: 2009-KK-062) for this study.

Informed Consent: N/A.

Peer-review: Externally peer-reviewed.

Author contributions: Concept - i.T., H.Y., K.B., A.A.; Design - I.T., H.Y., K.B., A.A.; Supervision - A.A.; Resource - D.D., S.E.G., B.D., A.A.; 
Materials - D.D., A.A.; Data Collection\&/or Processing - D.D., B.D., i.T., H.Y.; Analysis\&/or Interpretation - D.D., S.E.G., B.D., A.A.; Literature Search - D.D., S.E.G., B.D., A.A.; Writing - D.D., S.E.G., B.D., A.A.; Critical Reviews - S.E.G., K.B., A.A..

Acknowledgements: The authors would like to thank Dr Philip Robinson for help in manuscript preparation.

Conflict of Interest: No conflict of interest was declared by the authors.

Financial Disclosure: No financial disclosure was declared by the authors.

\section{References}

11. United Nations. Single Convention on Narcotic Drugs, 1961, as amended by the 1972 Protocol amending the Single Convention on Narcotic Drugs, 1961. http://www.incb.org/pdf/e/conv/ convention_1961_en.pdf. Accessed:08.05.2012.

2. United Nations. Convention on Psychotropic Substances, 1971. http://www.incb.org/pdf/e/conv/convention_1971_en.pdf. Accessed:08.05.2012.

3. United Nations. Convention Against Illicit Traffic in Narcotic Drugs and Psychotropic Substances, 1988. http://www.incb.org/ pdf/e/conv/1988_convention_en.pdf. Accessed:08.05.2012.

4. United Nations Office on Drugs and Crime (UNODC). Ensuring availability of controlled medications for the relief of pain and preventing diversion and abuse:Striking the right balance to achieve the optimal public health outcome. Vienna, 2011.

5. Republic of Turkey The Official Gazette. Circular letter regarding the prescriptions of substances and drugs subject to control. 29.05.1985, Number:5768. [T.C Resmi Gazete Kontrole Tabi Uyuşturucu Madde ve Müstahzarların Reçeteleri Hakkında Genelge. 29 Mayıs 1985, Sayı:5768].

6. Republic of Turkey The Official Gazette. Circular letter regarding the prescriptions of psychotropic medications. 02.01.1986, Number:09/2677. [T.C Resmi Gazete Psikotrop Ilaç Reçeteleri Hakkında Genelge. 02.01.1986, 09/2677].

7. World Health Organization (WHO). Improving access and use of psychotropic medicines (Mental health policy and service guidance package), 2005.

8. United Nations Office on Drugs and Crime (UNODC). World Drug Report 2011. United Nations Publication, Sales No. E.11. XI.10.

9. Prueksaritanond S, Tubtimtes $\mathrm{S}$, Pumkompol T, Sukying C. Psychotropic drug prescribing in the family medicine out-patient clinic, Ramathibodi Hospital. J Med Assoc Thai 2009;92:266-72.

10. Westbury JL, Jackson S, Peterson GM. Psycholeptic use in aged care homes in Tasmania, Australia. J Clin Pharm Ther 2010;35:189-93. [CrossRef]

11. Fortuna RJ, Robbins BW, Caiola E, Joynt M, Halterman JS. Prescribing of controlled medications to adolescents and young adults in the United States. Pediatrics 2010;126:1108-16. [CrossRef]

12. John U, Baumeister SE, Völzke H, Grabe HJ, Freyberger HJ, Alte D. Estimation of psycholeptic and psychoanaleptic medicine use in an adult general population sample using the Anatomical Therapeutic Chemical classification. Int J Methods Psychiatr Res 2008;17:220-31. [CrossRef]

13. Svab V, Subelj M, Vidmar G. Prescribing changes in anxiolytics and antidepressants in Slovenia. Psychiatr Danub 2011;23:17882.

14. McCabe SE, West BT, Teter CJ, Ross-Durow P, Young A, Boyd CJ. Characteristics associated with the diversion of controlled medications among adolescents. Drug Alcohol Depend 2011;118:452-8. [CrossRef]

15. Eggen AE. The use of controlled analgesics in a general population (15-59 years)-the influence of age, gender, morbidity, lifestyle and sociodemographic factors. Pharmacoepidemiol Drug Saf 1996;5:101-11. [CrossRef]
16. Fredheim OM, Log T, Olsen W, Skurtveit S, Sagen $\varnothing$, Borchgrevink PC. Prescriptions of opioids to children and adolescents; a study from a national prescription database in Norway. Paediatr Anaesth 2010;20:537-44. [CrossRef]

17. De Vries TPGM, Henning RH, Hogerzeil HV, Fresle DA. Guide to Good Prescribing. WHO/Action programme on essential drugs, Geneva, 1994

18. Bollan W, Simon C. Controlled drugs:regulations and prescribing. InnovAiT 2008;1:163-71. [CrossRef]

19. National Institute for Health \& Clinical Excellence (NICE). The NICE Guideline on diagnosis and management of ADHD in children, young people and adults. The British Psychological Society and The Royal College of Psychiatrists, London, 2009.

20. Subcommittee on Attention-deficit/Hyperactivity Disorder, Steering Committee on Quality Improvement and Management. ADHD:Clinical Practice Guideline for the Diagnosis, Evaluation, and Treatment of Attention-Deficit/Hyperactivity Disorder in Children and Adolescents. Pediatrics 2011;128:1-16. [CrossRef]

21. Canadian Attention Deficit Hyperactivity Disorder Resource Alliance (CADDRA). Canadian ADHD Practice Guidelines. 3th edition, 2010.

22. Somers JM, Goldner EM, Waraich P, Hsu L. Prevalence and incidence studies of anxiety disorders:a systematic review of the literature. Can J Psychiatry 2006;51:100-13.

23. Wolitzky-Taylor KB, Castriotta N, Lenze EJ, Stanley MA, Craske MG. Anxiety disorders in older adults:a comprehensive review. Depress Anxiety 2010;27:190-211. [CrossRef]

24. National Institute of Mental Health. Anxiety disorders in children and adolescents fact sheet. http://www.nimh.nih. gov/health/publications/anxiety-disorders-in-children-andadolescents/anxiety-disorders-in-children-and-adolescents.pdf. Accessed:08.05.2012.

25. Republic of Turkey Ministry of Development. Report of Health Education and Healthcare Human Resources in Turkey. Ankara, June 2010. ISBN:978-975-7912-37-8. [T.C Başbakanlık Devlet Planlama Teşkilatı Müsteşarlığı. Türkiye'de Sağlık Eğitimi ve Sağlık Insan Gücü Durum Raporu].

26. World Health Organization (WHO). Disease control priorities related to mental, neurological, developmental and substance abuse disorders. Switzerland, 2006.

27. World Health Organization (WHO). Gender and women's mental health, Gender disparities and mental health:The Facts. http:// www.who.int/mental_health/prevention/genderwomen/en/. Accessed:08.05.2012.

28. Kessler RC, Adler L, Barkley R, Biederman J, Conners CK, Demler $O$, et al. The prevalence and correlates of adult ADHD in the United States:results from the National Comorbidity Survey Replication. Am J Psychiatry 2006;163:716-23. [CrossRef]

29. Simon V, Czobor P, Bálint S, Mészáros A, Bitter I. Prevalence and correlates of adult attention-deficit hyperactivity disorder:metaanalysis. Br J Psychiatry 2009;194:204-11. [CrossRef]

30. Noto AR, de A Carlini E, Mastroianni PC, Alves VC, Galduróz JCF, Kuroiwa W, et al. Analysis of prescription and dispensation of psychotropic medications in two cities in the State of São Paulo, Brazil. Rev Bras Psiquiatr 2002;24:68-73. [CrossRef]

31. Ohayon MM, Lader MH. Use of psychotropic medication in the general population of France, Germany, Italy and the United Kingdom. J Clin Psychiatry 2002;63:817-25. [CrossRef]

32. Prueksaritanond $\mathrm{S}$, Tubtimtes $\mathrm{S}$, Pumkompol T, Sukying C. Psychotropic drug prescribing in the family medicine out-patient clinic, Ramathibodi Hospital. J Med Assoc Thai 2009;92:266-72.

33. Markovic-Pekovic V, Stoisavljevic-Satara S, Skrbic R. Outpatient utilization of drugs acting on nervous system:a study from the Republic of Srpska, Bosnia \& Herzegovina. Eur J Clin Pharmacol 2010;66:177-86. [CrossRef] 
34. Kanavos P, Üstel I, Font JC. Healthcare/Pharmaceutical Spending and Pharmaceutical Reimbursement Policy in Turkey. New Hope in Health Foundation (SUVAK), 2005.

35. Lieberman JA. The use of antipsychotics in primary care. Primary Care Companion J Clin Psychiatry 2003;5:3-8.

36. Ohayon MM, Caulet M, Priest RG, Guilleminault C. Psychotropic medication consumption patterns in the UK general population. J Clin Epidemiol 1998;51:273-83. [CrossRef]

37. United Nations. Report of the International Narcotics Control Board for 2010. New York, 2011. United Nations Publication Sales No. E.11.XI.1.
38. Seya MJ, Gelders SF, Achara OU, Milani B, Scholten WK. A first comparison between the consumption of and the need for opioid analgesics at country, regional, and global levels. J Pain Palliat Care Pharmacother 2011;25:6-18. [CrossRef]

39. Leong M, Murnion B, Haber PS. Examination of opioid prescribing in Australia from 1992 to 2007. Intern Med J 2009;39:676-81. [CrossRef]

40. Fredheim OM, Skurtveit S, Breivik H, Borchgrevink PC. Increasing use of opioids from 2004 to 2007 - pharmacoepidemiological data from a complete national prescription database in Norway. Eur J Pain 2010;14:289-94. [CrossRef] 